\title{
Thyrotoxic Periodic Paralysis- A Clinical Review
}

\author{
Srivastava $\mathrm{P}^{1}$, Rana $\mathrm{A}^{2}$, Anam $\mathrm{J}^{3}$ and Khare $\mathrm{J}^{4 *}$ \\ 1Senior Resident dept. of Dermatology, MGM Medical College, Mumbai, India \\ 2Student, MGM Medical College, Mumbai, India \\ ${ }^{3}$ Student, MGM Medical College, Mumbai, India \\ ${ }^{4}$ Assistant Professor Department of Medicine, MGM Medical College, Mumbai, India
}

Review Article

Volume 2 Issue 3

Received Date: August 11, 2018

Published Date: September 01, 2018

*Corresponding author: Jaideep Khare, MD Medicine, DNB Endocrinology, Assistant Professor department of Medicine, MGM Medical College, Mumbai, India, Tel: 09177816611; Email: drjaideepkhare@yahoo.com

\section{Abstract}

Thyrotoxic periodic paralysis (TPP) is not a uncommon condition often seen in Asian males characterized by sudden onset hyperthyroidism-related hypokalemia and paralysis. Intracellular shift of potassium due to activation of thyroid hormone sensitive $\mathrm{Na}^{+} / \mathrm{K}^{+}$ATPase is the possible pathological mechanism of hypokalemia, rather than depletion of potassium from the body, thus redistributive hypokalemia. Treatment involves correction of underlying hyperthyroidism, prevention of intracellular shift of potassium with non selective beta blockers and potassium replacement in emergency condition. Early identification of TPP is important for appropriate treatment and prevention of further episodes of hypokalemia or rebound hyperkalemia.

Keywords: Thyroid Periodic Paralysis; Hyperthyroidism; Hypokalemia

\section{Introduction}

Thyrotoxic periodic paralysis (TPP) is not a uncommon condition with an incidence of approximately $2 \%$ in patients with thyrotoxicosis of any cause [1].

TPP is a type of acute muscle weakness. Acute muscle weaknesses are of neurologic, metabolic and renal origin. Thyrotoxic periodic paralysis (TPP) is a metabolic type, potentially reversible electrolyte and muscle disorder characterized by acute muscle weakness, hypokalemia associated with hyperthyroidism.

TPP is commonly misdiagnosed in because its presentation has similarities with familial periodic paralysis. Familial periodic paralysis is an autosomal dominant disorder in which defect is in the gene coding for L-type calcium channel 1-subunit (CACNA1S) on chromosome 1q31-32 [1]. The neuromuscular presentations of both are similar, but presence of subtle features of hyperthyroidism in the presence of hypokalemic periodic paralysis favours the diagnosis of TPP.

Aim of this article is to review thyrotoxic periodic paralysis as a whole, the epidemiology, etiology, pathophysiology, clinical manifestations, laboratory findings, differential diagnosis, and management of TPP.

\section{Epidemology}

More frequently seen in patients of Asian or Hispanic origin; this shared predisposition has been linked to genetic variation in Kir2.6, a muscle-specific, thyroid 


\section{Open Access Journal of Endocrinology}

hormone-responsive $\mathrm{K}+$ channel [1,2]. More common in males than females suggests of differential action of androgen on $\mathrm{Na}^{+} / \mathrm{K}^{+}$ATPase activity. Seasonal variation seen with more frequency in summer probably due to loss of potassium ions in sweat which may further aggravate hypokalemia.

\section{Etiology and Pathophysiology}

Thyrotoxic periodic paralysis can occur in association with any of the causes of hyperthyroidism. The most common cause of TPP in hyperthyroidism is Graves disease and other includes toxic nodular goitre, iodine induced thyrotoxicosis, thyrotropin secreating pituitary adenoma, iatrogenic [2-5].

The hypokalemia in TPP is attributed to both direct and indirect activation of the $\mathrm{Na}+/ \mathrm{K}+-\mathrm{ATPase}$, resulting in increased uptake of $\mathrm{K}+$ by muscle and other tissues. Hypokalemia is usually profound and almost invariably accompanied by hypophosphatemia and hypomagnesemia. Studies have shown that $\mathrm{Na}+\mathrm{K}+-$ ATPase pump activity in platelets and skeletal muscle cells was increased in patients with thyrotoxicosis and periodic paralysis compared with patients with thyrotoxicosis and no paralysis $[2,5,6]$.

Hyperthyroidism results in a hyper adrenergic state. $\beta$-Adrenergic stimulation in muscle cells may directly induce cellular potassium uptake by increasing intracellular cyclic adenosine monophos- phate leading to activation of the $\mathrm{Na}+\mathrm{K}+-\mathrm{ATPase}$ pump [1]. Moreover, thyroid hormone per se directly stimulates $\mathrm{Na}+\mathrm{K}+-$ ATPase pump and increases the number and sensitivity of $\beta$-receptors, which further increase catechol- aminemediated potassium uptake.The chemical structure of thyroxine is similar to that of catecholamines, exerting its cellular effect via catecholamine receptors. This may explain why nonselective $\beta$-blockers are useful for treatment of TPP associated with hypokalemia $[5,6]$.

Hyperinsulinemia observed in patients with a sudden attack of TPP indirectly stimulates $\mathrm{Na}+, \mathrm{K}+-$ ATPase pump and participates in the pathogenesis of hypokalemia. The increase in plasma insulin concentration is associated closely with a high- carbohydrate diet and sympathetic stimulation on insulin release from beta cells of the pancreas as hyper adrenergic activity in TPP [6,7].

\section{Clinical Features}

1. The initial episode of TPP is seen mostly in person aged $20-40$ years.
2. Prodromal symptoms include muscle aches, cramps and muscle stiffness. Weakness usually begins in proximal muscles of lower extremities and can progress to flaccid quadriplegia which is usually symmetrical.

3. Bulbar, respiratory and ocular muscles are usually spared, along with mental functions and sensation.

4. High carbohydrate diet and strenous exercise are well recognized precipitating factor for TPP.

5. TPP does not occur during exercise but during a period of rest after exercise.

6. Other precipitating factors include trauma, cold exposure, infection, menstruation and emotional stress.

7. Typical clinical symptoms of hyperthyroidism i.e. weight loss, palpitations, heat intolerance, increased appetite and diaphoresis may be subtle. Reportedly, near half of patients with TPP have no obvious symptoms related to hyperthyroidism during an attack.

8. Spontaneous resolution of attacks occur in few hours to 2 days, even without potassium supplementation.

9. Cardiac arrhythmias and respiratory failure are possible complications.

10. Between attacks, patients with TPP are neuromuscularly symptom free and do not exhibit muscle weakness or atrophy seen in thyrotoxic myopathy.

11. Adapted from references $1,3,7,8,9,10$

\section{Laboratory Findings}

\section{Blood Electrolyte Findings}

Hypokalemia is the most consistently found electrolyte abnormality in TPP and is believed to be a primary source of paralysis [1,2]. In recent reports, hypophosphatemia another cause of muscle weakness was seen commonly in patients with TPP $[8,9]$.

\section{Blood Acid Base Findings}

Blood acid base imbalance is usually not prominent in patients with intracellular shift of potassium in TPP. This is because total amount of extracellular potassium entering the cells must be exchanged with intracellular sodium and hydrogen to maintain electro neutrality [10].

\section{Urinary Potassium Findings}

The urinary pottasium excretion rate must be low in patients with TPP because hypokalemia is caused by increased shift of potassium into cells. To circumvate the drawback of using urinary pottasium concentration alone, urinary potassium creatinine ratio and transtubular potassium gradient can be used which is usually less $2 \mathrm{mEq} / \mathrm{mmol}$ and 3 , respectively [1]. 


\section{Open Access Journal of Endocrinology}

\section{Urinary Calcium and Phosphorous Findings}

Hyperthyroidism is characterised by accelerated bone turnover resulting from direct stimulation of bone cells by high concentration of thyroid hormone [11]. Infact, hypercalciuria and hyperphosphaturia have been reported in patients with hyperthyroidism. In contrast to hyperphosphaturia often found in hyperthyroidism, urinary phosphate excretion is reduced remarkably as result of increased shift of pottasium into the cells in patients with TPP [12].

\section{Electrocadigraphic Findings}

The distinct ECG features in TPP include sinus tachycardia or sinus, high QRS voltage and wenckebach atrioventricular block [13].

\section{Electromyographic Findings}

Because TPP is an acquired form of periodic paralysis, electromyogarphic studies during attack of TPP show a low amplitude action potential(CMAP) of the tested muscles and muscular in excitability in response to direct electrical stimulation that disappears during remission [14].

This indicates defect lies in the muscle itself.

Hence electrophysiological excercise test can be used as a diagnostic tool for TPP because excercise can induce weakness in periodic paralysis [15].

\section{Management}

\section{Emergency Treatment}

Body potassium stores are normal in TPP thus the aim of pottasium supplementation is to normalize the plasma potassium concentration instead of correcting a pottasium deficit.

The traditional treatment of severe attack is intra venous or oral potassium chloride administration to hasten muscle recovery and to prevent cardiac arrhythmia and respiratory arrest.

However rebound hyperkalemia can develop as result of exogenous pottasium supplementation after paralysis subsides [1].

\section{Definitive Treatment}

Definitive control of hyperthyroidism completely abolishes the attack of TPP and includes antithyroid drugs, surgical thyroidectomy and radioiodine therapy.
Propanalol non selective beta blocker has long been recognised as efficacious in preventing recurrent attack of TPP by suppresing activity of Na/K ATPase $[16,17]$.

\section{Conclusion}

Thyrotoxic periodic paralysis (TPP) is not a uncommon condition and early identification of TPP is important for appropriate treatment and prevention of further episodes of hypokalemia or rebound hyperkalemia.

\section{References}

1. Lam L, Nair RJ, Tingle L (2006) Thyrotoxic periodic paralysis. Proceedings. Baylor University Medical Center Proceedings 19(2): 126-129.

2. Lin SH, Huang CL (2012) Mechanism of Thyrotoxic Periodic Paralysis. J Am Soc Nephrol 23(6): 985-988.

3. Ober KP (1992) Thyrotoxic periodic paralysis in the unites states: report of 7 cases and review of the literature. Medicine(Baltimore) 71(3): 109-120

4. Hsu FS, Tsai WS, Chau T, Chen HH, Chen YC, et al. (2003) Thyrotropin- secreting pituitary adenoma presenting as hypokalemic periodic paralysis. Am J Med Sci 325(1): 48-50.

5. Chan A, Shinde R, Chow CC, Cockram CS, Swaminathan R (1991) In vivo and in vitro sodium pump activity in subjects with thyrotoxic periodic paralysis. BMJ 303(6810):1096-1099.

6. Chan A, Shinde R, Chow CC, Cockram CS, Swaminathan R (1994) Hyperinsulinaemia and $\mathrm{Na}+$, $\mathrm{K}(+)$ - ATPase activity in thyrotoxic periodic paralysis. Clin Endocrinol (Oxf) 41(2): 213-216.

7. Belayneh DK, Kellerth $\mathrm{T}$ (2015) Thyrotoxic hypokalemic periodic paralysis in an African male: a case report. Clin Case Rep 3(2): 102-105.

8. Guthrie GP, Curtis JJ, Beilman KM (1978) Hypophosphatemia in thyrotoxic periodic paralysis. Arch Intern Med 138(8): 1284-1285.

9. Norris KC, Levine B, Ganesan K (1996) Thyrotoxic periodic paralysis associated with hypokalemia and hypophosphatemia. Am J Kidney Dis 28(2): 270-273.

10. Lin SH, Davids MR, Halperin ML (2003) Hypokalemia and paralysis QJM 94(3): 133-139. 


\section{Open Access Journal of Endocrinology}

11. Mosekilde L, Eriksen EF, Charles P (1990) Effects of thyroid hormones on bone and mineral metabolism. Endocrinal Metab Clin North Am 19(1): 35-63.

12. Lin YF, Wu CC, Pei D, Chu SJ (2003) Lin Diagnosing thyrotoxic periodic paralysis in the ED. Am J Emerg Med 21(4): 339-342.

13. Hsu YJ, Lin YF, chau T, Lin SH, Kuo SW, et al. (2003) Electrocardiographic manifestations in patients with thyrotoxic periodic paralysis. Am J Med Sci 326(3): 128-132.

14. Kelley DE, gharib H, Kennedy FP, Duda RJ, McManis PG (1989) Thyrotoxic periodic paralysis: report of 10 cases and review of electromyographicfindings. Arch Intern Med 149(11): 2597-2600.

15. McManis PG, Lambert EH, Daube JR (1989) The excercise test in periodic paralysis. Muscle nerve 9(8): 704-710.

16. Yeung RT, Tse TF (1974) Thyrotoxic periodic paralysis: effect of propanolol. Am J Med 57(4): 584590.

17. Goh SH (2002) Thyrotoxic periodic paralysis: reports of seven patients presenting with weakness in an asian emergency department. Emerg Med J 19(1): 7879.

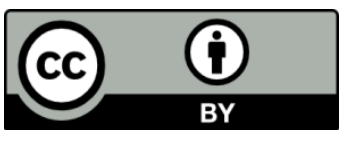

